\title{
Balancing Upstream and Downstream Measures to Tackle the Obesity Epidemic: A Position Statement from the European Association for the Study of Obesity
}

\author{
Harry Rutter ${ }^{a} \quad$ Maira Bes-Rastrollo ${ }^{b}$ Stefaan de Henauw ${ }^{c}$ \\ Marjaana Lahti-Koskid Susanna Lehtinen-Jacks ${ }^{e}$ Dana Mullerova ${ }^{f}$ \\ Finn Rasmusseng ${ }^{g} \quad$ Aila Rissanen ${ }^{\mathrm{h}} \quad$ Tommy L.S. Visscher $^{\mathrm{i}} \quad$ Lauren Lissner $^{\mathrm{j}}$ \\ ${ }^{a}$ ECOHOST - The Centre for Health and Social Change, London School of Hygiene and \\ Tropical Medicine, London, UK; ${ }^{\mathrm{b}}$ Department of Preventive Medicine and Public Health, \\ University of Navarra, and CIBERobn, Instituto de Salud Carlos III, and Navarra's Health \\ Research Institute (IDISNA), Pamplona, Spain; ' Department of Public Health, Faculty \\ of Medicine and Health Sciences, Ghent University, Ghent, Belgium; ${ }^{\mathrm{d}}$ Finnish Heart \\ Association, Helsinki, Finland; e Faculty of Social Sciences (SOC) / Health Sciences, University \\ of Tampere, Tampere, Finland; ${ }^{f}$ Department of Public Health and Preventive Medicine, \\ Faculty of Medicine in Pilsen, Charles University, Plzeň, Czech Republic; ${ }^{9}$ Department of \\ Health Sciences, Lund University, Lund, Sweden; ' $\mathrm{O}$ Obesity Research Unit, Diabetes and \\ Obesity Research Program Unit, University of Helsinki, Helsinki, Finland; 'Research Group \\ Healthy Cities, Windesheim University of Applied Sciences, Zwolle, The Netherlands; \\ iSection for Epidemiology and Social Medicine (EPSO), Sahlgrenska Academy, University of \\ Gothenburg, Gothenburg, Sweden
}

Key Words

Obesity $\cdot$ Complexity $\cdot$ Systems $\cdot$ Stigma $\cdot$ Upstream $\cdot$ Public health

The increasing prevalence of obesity in Europe and elsewhere is the outcome of a complex system that incorporates multiple influences [1]. Public and political discourse on obesity focus strongly on the role of the individual, often framing obesity as a failure of willpower and placing the onus of responsibility on people themselves. However, although decision-making at an individual level is a factor in obesity, the choices people make are largely shaped by the environments in which they live and the opportunities available to them to engage in healthy eating and regular physical activity.

Promoting healthy body weight in the population requires a whole system response that includes upstream initiatives to tackle these 'obesogenic' environments. National and international actions such as trade treaties, fiscal measures, and regulation of the food industry, 
Rutter et al.: Balancing Upstream and Downstream Measures to Tackle the Obesity Epidemic: A Position Statement from the European Association for the Study of Obesity

as well as national and local actions involving design of the built environment and transport systems, provision of public green space, and regulation of retail and fast-food outlets can improve health and help to prevent obesity. These structural measures can support a range of individual decisions promoting healthy diets, increased physical activity, and reduced sedentary behaviors. Many upstream actions to promote active transport and a healthier food system are also aligned with wider sustainability goals, leading to environmental and health co-benefits [2,3]. At a population level, minor changes affecting large numbers of people may have a greater overall health impact than those with a large impact on small numbers of people [4].

Numerous aspects of modern life act as barriers to healthy eating and regular physical activity. Many of these barriers are socially patterned in such a way that the most disadvantaged members of society experience the greatest obstacles to healthy living. There is thus a need for what has been described as 'proportionate universalism' - tackling the causes of the causes across society, but in a way that does so most strongly for those with the greatest need [5].

There is growing acknowledgment that society as a whole must act to address the obesity epidemic. Individually-oriented responses to obesity often depend upon high levels of personal agency, and may thus contribute to widening inequalities [6]. Moreover, when problems are framed largely as the result of a failure of willpower, this promotes stigmatization of individuals affected by overweight or obesity. Scientists, clinicians, managers, and legislators as well as the public must all work together to drive improvements, as recognized in the recent Milan Declaration of the European Association for the Study of Obesity [7]. While the need for individual-level responses remains, both through the healthcare system and more widely, these need to be supported and augmented by a much greater number and intensity of upstream health policies and legislation. This will improve health outcomes, reduce health inequalities, contribute to reducing stigma, and generate a wide range of environmental co-benefits.

\section{Key Points}

Public health actions to tackle obesity have historically focused on individual-level changes to diet and physical activity, rather than the upstream actions required to alter the structural drivers of behaviour.

This focus on individual-level behavior has many limitations. It may well widen inequalities and increase obesity-related stigma, and it diverts attention away from much needed changes to structural and environmental determinants of health.

Although individual-level changes are a necessary component of obesity prevention, they are only one part of a whole system response, and must be supported by upstream actions that focus on promoting healthier physical, economic and social environments.

Actions promoting universal prevention translate into reduced chronic disease burden, increased productivity, economic savings, improved quality of life, and protection of the environment.

\section{Disclosure Statement}

HR was supported by the National Institute for Health Research (NIHR) Collaboration for Leadership in Applied Health Research and Care (CLAHRC) North Thames at Bart's Health NHS Trust. TV is an unpaid member of the EPODE International Network's scientific committee. The EPODE methodology includes public-private partnerships. His university receives budget for his participation in international EPODE meetings. The authors have no other interests to declare. 
Rutter et al.: Balancing Upstream and Downstream Measures to Tackle the Obesity Epidemic: A Position Statement from the European Association for the Study of Obesity

\section{References}

1 Butland B, Jebb SA, Kopelman P, McPherson K, Thomas S, Mardell J, Parry V: Foresight. Tackling Obesities: Future Choices. London, Government Office for Science, 2007. https://pdfs.semanticscholar.org/b910/e21b81 d6caa1d15040b2b69d621554716692.pdf (last accessed January 25, 2017).

2 Ganten D, Haines A, Souhami R: Health co-benefits of policies to tackle climate change. Lancet 2010;376: 1802-1804.

3 Transforming Our World: The 2030 Agenda for Sustainable Development. New York, United Nations, 2015 https://sustainabledevelopment.un.org/post2015/transformingourworld (last accessed January 25, 2017).

4 Rose G: Strategy of prevention: lessons from cardiovascular disease. BMJ 1981;282:1847-1851.

5 Marmot M (chair): for the Strategic Review of Health Inequalities in England post-2010: Fair Society, Healthy Lives. The Marmot Review. 2010. www.instituteofhealthequity.org/projects/fair-society-healthy-lives-themarmot-review (last accessed January 25, 2017).

6 Adams J, Mytton O, White M, Monsivais P. Why Are Some Population Interventions for Diet and Obesity More Equitable and Effective Than Others? The Role of Individual Agency. PLoS Med. 2016;13(4):e1001990.

7 Frühbeck G, Sbraccia P, Nisoli E, Woodward E, Yumuk V, Farpour-Lambert NJ, Halford JGC, Toplak H, Carruba MO: 2015 Milan Declaration: a call to action on obesity - an EASO position statement on the occasion of the 2015 EXPO. Obes Facts 2016;9:296-298. 